Provided by the author(s) and University of Galway in accordance with publisher policies. Please cite the published version when available.

\begin{tabular}{|c|l|}
\hline Title & $\begin{array}{l}\text { Controlling dispersion of axonal regeneration using a } \\
\text { multichannel collagen nerve conduit }\end{array}$ \\
\hline Author(s) & Yao, Li; Pandit, Abhay \\
\hline $\begin{array}{c}\text { Publication } \\
\text { Date }\end{array}$ & 2010-03-21 \\
\hline $\begin{array}{c}\text { Publication } \\
\text { Information }\end{array}$ & $\begin{array}{l}\text { Yao, L., de Ruiter, G. C. W., Wang, H., Knight, A. M., } \\
\text { of axonal regeneration using a multichannel collagen nerve } \\
\text { conduit. Biomaterials, 31(22), 5789-5797. }\end{array}$ \\
\hline $\begin{array}{c}\text { Publisher } \\
\text { Elsevier }\end{array}$ \\
\hline $\begin{array}{c}\text { Link to } \\
\text { publisher's } \\
\text { version }\end{array}$ & http://dx.doi.org/10.1016/j.biomaterials.2010.03.081 \\
\hline $\begin{array}{c}\text { Item record } \\
\text { http://hdl.handle.net/10379/1619 }\end{array}$ \\
\hline
\end{tabular}

Downloaded 2023-04-26T10:28:32Z

Some rights reserved. For more information, please see the item record link above. 


\section{Controlling Dispersion of Axonal Regeneration using a Multichannel Collagen Nerve Conduit}

Li Yao ${ }^{\text {a,b }}$, Godard C.W. de Ruiter ${ }^{\mathrm{c}, \mathrm{e}}$, Huan Wang ${ }^{\mathrm{c}}$, Andrew M. Knight ${ }^{\mathrm{b}}$, Robert J. Spinner ${ }^{\mathrm{c}}$, Michael J. Yaszemski ${ }^{d}$, Anthony J. Windebank ${ }^{b}$, Abhay Pandit ${ }^{a, *}$

a Network of Excellence for Functional Biomaterials, National Centre for Biomedical Engineering Science, National University of Ireland Galway, Ireland

b Department of Neurobiology, Mayo Clinic, Rochester, MN 55905, USA

c Department of Neurosurgery, Mayo Clinic, Rochester, MN 55905, USA

d Department of Orthopaedics, Mayo Clinic, Rochester, MN 55905, USA

e Department of Neurosurgery, Leiden University Medical Center, The Netherlands

*Corresponding author:

Abhay Pandit

Network of Excellence for Functional Biomaterials (NFB)

National University of Ireland, Galway, IDA Business Park, Dangan, Galway, Ireland

Phone:, 00353 (0) 91492758

Fax: $00353(0) 91495585$.

E-mail address: abhay.pandit@nuigalway.ie

Running head: Multichannel collagen conduits for nerve regeneration 
PAGE 2

\section{ABSTRACT}

Single channel conduits are used clinically in nerve repair as an alternative to the autologous nerve graft. Axons regenerating across single channel tubes, however, may disperse resulting in inappropriate target reinnervation. This dispersion may be limited by multichannel nerve conduits as they resemble the structure of nerve multiple basal lamina tubes. In this study, we investigated the influence of channel number on the axonal regeneration using a series of 1-, 2-, 4-, and 7-channel collagen conduits and commercial $\left(\right.$ NeuraGen $\left.^{\circledR}\right)$ single channel conduits. Nerve conduits were implanted in rats with a $1 \mathrm{~cm}$ gap of sciatic nerve. After four months, quantitative results of regeneration were evaluated with nerve morphometry and the accuracy of regeneration was assessed using retrograde tracing: two tracers being applied simultaneously to tibial and peroneal nerves to determine the percentage of motor neurons with double projections. Recovery of function was investigated with compound muscle action potential recordings and ankle motion analysis. We showed that the fabricated 1-channel and 4-channel conduits are superior to other types of conduits in axonal regeneration. Simultaneous tracing showed a significantly lower percentage of motor neurons with double projections after 2- and 4-channel compared with 1-channel conduit repair. This study shows the potential influence of multichannel guidance on limiting dispersion without decreasing quantitative results of regeneration.

Key words: collagen, nerve regeneration, nerve conduit, neural tissue engineering, in vivo 


\section{Introduction}

Peripheral nerve injuries can be caused by trauma and iatrogenic injury. In the majority of nerve injuries, the nerve ends cannot be directly apposed and a nerve graft is needed to bridge the defect. Though an autologous nerve graft is the gold standard of nerve graft repair, it has several disadvantages, including the need for an extra incision, loss of donor nerve function, mismatch in size between the donor nerve and the injured nerve, and a limited availability of donor nerve. A diverse array of synthetic and natural materials has been studied in peripheral nerve repair, but these studies have shown limited success [1-12].

In the recent history nerve regeneration studies have been performed predominantly on single channel conduits. However, axons regenerating across a single channel nerve tube might disperse, resulting in inappropriate target reinnervation [13]. Multichannel conduits, fabricated from poly(lactide-co-glycolide), showed promise for directed nerve growth over short observation times (six weeks) and limited gap size (7 $\mathrm{mm}$ ) [14]; however, swelling has been shown in in vitro and in vivo studies to close the conduit cavities and block axonal growth over long-term study (twelve weeks) and larger gap sizes (10 mm) $[15,16]$. The precise function of multichannel on limiting dispersion compared with single channel nerve tubes has not been explored due to the dimensional instability of the synthetic polymer [16]. A multichannel nerve conduit with structural stability and favorable material and mechanical properties is needed to provide a reliable platform from which to investigate this mechanism.

To investigate the influence of multichannel structure on axonal regeneration across nerve tubes for this study, we developed a series of 1-, 2-, 4- and 7-channel conduits made from collagen. Collagen is a naturally occurring protein that is ubiquitous among mammalian species. It plays an important role in the formation of the nerve tissue matrix. For example, the basal lamina tubes (endoneural sheath) that surround the axonSchwann cell units consist of collagen, and the epineural and perineuial sheaths (that surround the nerve fascicles and strengthen the nerve) consist of longitudinal oriented collagen fibrils. This matrix also plays an important role in the regeneration process $[17,18]$. Collagen have been used for the fabrication of nerve tubes $[19,20]$, and single channel collagen tubes are already commercially available: NeuraGen ${ }^{\circledR}$ (Integra), NeuroMatrix ${ }^{\circledR}$ and Neuroflex ${ }^{\circledR}$ (both Stryker). We fabricated a series of multichannel collagen conduits by molding and crosslinking (with 1-ethyl-3-(3-dimethylaminopropyl) carbodiimide (EDC) in $\mathrm{N}$ - 
hydroxysuccinimide (NHS)). The conduits were then implanted in a $1 \mathrm{~cm}$ gap of the rat sciatic nerve. In this study, quantitative results of regeneration were analyzed with compound muscle action potential (CMAP) recordings and quantitative nerve morphometry. Qualitative measures of regeneration included simultaneous retrograde axonal tracing and ankle motion analysis. Finally comparison was carried out between these results and those obtained with an autograft and with a commercially available conduit (Neuragen ${ }^{\circledR}$ from Integra).

\section{Materials and methods}

\subsection{Fabrication of multichannel nerve conduits}

Cylindrical molds with 4 and 7 channels were constructed. Channel internal diameter for 4-channel and 7channel molds were $530 \mu \mathrm{m}$ and $410 \mu \mathrm{m}$ respectively (Fig. $1 \mathrm{~A}$ and B). To fabricate the 4 - and 7-channel conduits, constructs were made with 4 and 7 stainless steel wires inserted into two molds. To fabricate the 2channel conduit, two wires were symmetrically inserted into the 2 channels of 4 -channel molds. The distance between the two parts was kept at $1 \mathrm{~cm}$. Collagen solution $(12 \mathrm{mg} / \mathrm{ml}$, in $10 \mathrm{mM} \mathrm{HCL})$ was evenly placed around the wires and part of the molds and air-dried (Fig. 1C). To make the 1-channel conduit, collagen solution was placed and air-dried on a single stainless steel wire (diameter $1.5 \mathrm{~mm}$ ). Collagen was then treated with crosslinking solution (EDC (30 mM) and NHS (10 mM) in MES solution (50 mM; PH 5.5)) overnight. After washing with $\mathrm{NaH}_{2} \mathrm{PO}_{4}(0.1 \mathrm{M})$ and distilled water [21], collagen was freeze-dried on the wire. Molds and wires were removed from the collagen conduits after freeze-drying.

\subsection{Animal procedures and experimental groups}

In this study a total of 72 adult female Lewis rats, weighing between 190-220 gr, were used. All experimental procedures were conducted according to animal care guidelines of the Mayo Foundation Institutional Animal Care and Use Committee. In the first experimental group, for the study of nerve morphometry and CMAP recording, 48 rats were randomly assigned to 6 subgroups: autograft, 1-, 2-, 4- and 7-channel collagen conduits, and the commercial single channel collagen conduit (NeuraGen ${ }^{\circledR}$, Integra Life Sciences Corporation, USA). In the second experimental group, for the study of simultaneous retrograde 
tracing, ankle motion analysis and CMAP recording, 24 rats were randomly assigned to four subgroups: autograft, 1-, 2- and 4-channel conduits. In this latter group, treadmill training (running speed 15m/min, duration 10 minutes [22-24]) was performed, one week post operation, and then four times per week for eight weeks in total to prevent formation of contractures.

\subsection{Surgical procedure}

Rats were anesthetized using $80 \mathrm{mg} / \mathrm{kg}$ of ketamine and $5 \mathrm{mg} / \mathrm{kg}$ of xylazine, that was injected intraperitoneally. Dissection was performed with the aid of a Zeiss operating microscope (Carl Zeiss, Inc., Oberkochen, Germany). The left sciatic nerve was exposed and isolated at the midthigh level using a dorsallateral approach. A 5mm segment of the sciatic nerve was resected before the bifurcation of the nerve into the tibial and peroneal nerve branches. The proximal and distal nerve ends were inserted $1 \mathrm{~mm}$ into the $12 \mathrm{~mm}$ long tubes with 10-0 monofilament nylon sutures (Ethilon; Ethicon, Inc., Piscataway, NJ) [25]. The wound was subsequently closed in layers (Supplemental Fig 1). The same procedure was performed for autologous nerve graft repair, except that a $1 \mathrm{~cm}$ segment of sciatic nerve was transected and microsurgically repaired with 10-0 monofilament nylon sutures.

\subsection{Nerve morphometry}

After 16 weeks of implantation, in all animals of the first experimental group, the graft was re-exposed and fixed in situ with a Trump solution (4\% formaldehyde and 1\% glutaraldehyde in phosphate buffered solution) for 30 minutes [26]. The graft was resected and placed in the same fixative overnight. Specimens (2 $\mathrm{mm})$ at the midpoint of the graft were collected and embedded in spur resin. Sections $(1 \mu \mathrm{m})$ were cut with a glass knife on an ultramicrotome (Leica EMUC6 ultracut, Wetzlar, Germany). The sections of each specimen were stained with toluidine blue or $1 \%$ phenylenediamine for nerve morphometry. Nerve morphometry was performed [26] on a image analysis system. Briefly, the inner and outer border of myelinated fibers was manually drawn for at least 500 myelinated fibers at $63 \times$ magnification in randomly selected areas in the slide

to determine the number of myelinated fibers, the density of myelinated fibers, the mean diameter of myelinated fibers and the mean myelin thickness. SS 


\subsection{Compound muscle action potential recording}

In all animals of both experimental groups, CMAPs were recorded before operation, 6, 8, 10, 12 and 16 weeks after nerve conduit implantation. Briefly, animals were first anesthetized with the procedure described above (surgical procedure), then CMAPs were recorded with an electromyography machine (Nicolet Viking IV; Viasys Healthcare, Inc., Conshohocken, PA) in the tibial and peroneal nerve-innervated foot muscles of the left limb. Needle recording electrodes were placed in the plantar or dorsal foot muscles referenced to needle electrodes placed distally in the foot digits. Needle-stimulating electrodes were placed directly posterior to the tibia with approximately $5 \mathrm{~mm}$ between the distal cathode and proximal anode. The stimulating electrodes were adjusted locally to produce the maximal CMAP amplitude. The stimulus was increased incrementally to produce a supramaximal response. CMAPs were recorded and analyzed for the amplitude of the action potential.

\subsection{Ankle motion analysis}

In the second experimental group, ankle motion was analyzed before surgery, 1 week, 6 weeks, 12 weeks and 16 weeks after repair [27]. Three markers were labeled on the left leg on bony landmarks of the tibia, lateral malleolus, and fifth metatarsal. Markers were tattooed to enhance the reproducibility of marker placement. Rats were filmed in a one meter long plexiglass runway with a black box on one end, which was alternately switched to the other end to get the rats to walk. The animal walking was filmed using a $60 \mathrm{~Hz}$ digital camera (Dinion XF CCD Camera; Bosch Security Systems, Fairport, New York). After filming, the digital videos were processed using motion analysis software (Vicon Peak, Centennial, Colorado) that automatically tracks the markers on the leg of the rat in each frame of the video. The ankle joint motion was analyzed and the value of the ankle angle was compared at different moments during the step cycle: midstance (MSt), the moment the right foot in the air crosses the left foot in the stance (that bears the weight); terminal stance (TS), the moment the left foot comes off the runway (in normal animals, the moment of maximum plantar flexion); and midswing (MSw), the moment the left foot crosses the right foot in the stance (in normal animals, the moment of maximal dorsiflexion). Data for the ankle angles were reported in degrees of the intersection angle of the line connecting tibia and lateral malleolus and the line connecting lateral malleolus and fifth metatarsal. 


\subsection{Simultaneous retrograde tracing}

In the second experimental group, after sixteen weeks, all animals were anesthetized for simultaneous retrograde tracing [16]. The nerve graft and distal tibial and peroneal nerve branches were exposed. First the peroneal nerve was transected and the proximal end was placed in a cup with $5 \%$ diamidino yellow (DY) (EMS-Chemie, Mannedorf, Switzerland) solution for 20 minutes. After that, the nerve end was cleaned, then sutured into and covered by surrounding fat tissue to prevent tracer leakage and cross-contamination. Then the tibial nerve was transected and the proximal nerve end was placed in a cup with $5 \%$ fast blue (FB) (EMSChemie, Mannedorf, Switzerland) solution for 20 minutes (Supplemental Fig. 2). Again, the nerve end was cleaned and then sutured into and covered by surrounding fat tissue. Six days after tracer application, the animals were transcardially perfused with $4 \%$ paraphormaldehyde and $10 \%$ sucrose in phosphate buffered solution (PBS). Spinal cord segments L1 to L6 were removed and post-fixed overnight. Sagittal longitudinal $30 \mu \mathrm{m}$-thick sections were cut on a cryostat (LEICA Cryostat, CM3050S, Nussloch, Germany) at $-20^{\circ} \mathrm{C}$. Sections were immediately evaluated under a fluorescent microscope (Axioplan 2; Carl Zeiss, Inc.). Neuronal profiles with blue cytoplasm and a dark nucleus were counted as FB-labeled, profiles with a yellow nucleus and dark cytoplasm as DY-labeled, and profiles with a yellow nucleus and blue cytoplasm as FB-DY-doublelabeled profiles. All profiles in all sections were counted.

\subsection{Statistical analysis}

The data were expressed as means $\pm S D$ and analyzed by using oneway ANOVA (post-hoc Bonferroni) with SPSS version 17.0 software package (SPSS Inc., Chicago, IL, USA). P values less than 0.05 were considered statistically significant. 


\section{Results}

\subsection{Nerve morphometry}

Successful regeneration (defined for the presence of myelinated axons at the middle of the conduit) was observed in 39 out of 40 cases of conduit repair (in one 2-channel conduit graft only fibrous tissue was present). Figures 2, 3 and 4 show microscopic images (taken at $5 \times$ magnification (Fig. 2) and 40x magnification (Fig. 3 and 4)) of sections taken through the middle of all 6 types of grafts.

The mean number of fascicles (channels filled with myelinated axons) was one for the single channel conduits, $1.6 \pm 0.8$ for the 2 -channel conduits, $3.75 \pm 0.4$ for the 4-channel conduits, and $6 \pm 1$ for the 7 channel conduits. The mean number of myelinated fibers was not significantly different between conduit groups (Fig. 5A), but was significantly higher after autograft repair (10348 \pm 1038 , vs all conduit groups, $\mathrm{p}<0.01$ ). The mean density of myelinated fibers (Fig. 5B) was significantly higher for the 2-channel conduit group (vs autograft, 1-channel conduit, commercial conduit, $\mathrm{p}<0.05$ ), and significantly lower for the commercial conduit group (vs all the other groups, $\mathrm{P}<0.01$ ).

The myelinated fiber diameter (Fig. 5C) of the single-channel conduit group (4.37 $\pm 0 \mu \mathrm{m}$ ) was significantly higher than the 2-, 7-channel and commercial conduit groups $(p<0.01)$. The myelinated fiber diameter of the autograft and 4-channel conduit groups (4.08 $\pm 0.37 \mu \mathrm{m}$ and $4.27 \pm 0.19 \mu \mathrm{m}$ respectively) were significantly higher than the commercial conduit graft group $(3.64 \pm 0.20 \mu \mathrm{m} ; \mathrm{P}<0.05)$. The myelination thickness (Fig. 5D) of the autograft group $(0.67 \pm 0.13 \mu \mathrm{m})$ was significantly higher than those of the 7-channel conduit $(0.57 \pm 0.03$ $\mu \mathrm{m} ; \mathrm{p}<0.05)$ and commercial conduit groups $(0.52 \pm 0.03 \mu \mathrm{m} ; \mathrm{p}<0.01)$. The myelination thickness of the 1 channel and 4-channel conduit groups $(0.66 \pm 0.07 \mu \mathrm{m}$ and $0.64 \pm 0.0 .05 \mu \mathrm{m}$ respectively) was significantly higher than that of the commerical conduit group $(p<0.05)$.

\subsection{Compound muscle action potential recording}

In the first experimental group for the study of nerve morphometry and CMAP recording the first CMAPs were detected six weeks after autograft repair and eight weeks after single channel conduit repair (Fig. 6A and B). The CMAP amplitude of all the experimental groups increased with time. At twelve weeks, the amplitude of the autograft group in the plantar muscles and dorsal foot muscles $(2.08 \pm 0.94 \mathrm{mV}$ and $2.25 \pm$ 
$1.16 \mathrm{mV}$ respectively) was significantly higher than those of the other groups $(p<0.01)$. At sixteen weeks, the CMAP amplitude of the autograft nerve in the plantar foot muscles and in the dorsal muscles $(3.95 \pm 0.83 \mathrm{mV}$ and $3.38 \pm 1.18 \mathrm{mV}$ respectively) was significantly higher than those of the 2-, 4-, 7-channel and commercial conduit groups $(p<0.01)$. The CMAP amplitude of the 1- and 4-channel conduit groups in the plantar foot muscles $(2.35 \pm 0.80 \mathrm{mV}$ and $1.90 \pm 0.70 \mathrm{mV}$ respectively) was significantly higher than that of the 7-channel conduit group $(0.63 \pm 0.56 \mathrm{mV}, \mathrm{p}<0.05)$. The CMAP amplitude of the 1-channel conduit group in the dorsal foot muscles $(2.08 \pm 0.89 \mathrm{mV})$ was significantly higher than that of the 7-channel group $(0.38 \pm 0.44 \mathrm{mV}$, $\mathrm{p}<0.01)$. The comparison of CMAPs at sixteen weeks was made between the first experimental group without treadmill training and the second experimental group with treadmill training in figures $6 \mathrm{C}$ and $\mathrm{D}$. The CMAP amplitude of the 4-channel group in the plantar foot muscles $(3.43 \pm 0.70 \mathrm{mV})$ with treadmill training was significantly higher than that of the non-training group $(p<0.05)$.

\subsection{Simultaneous retrograde tracing}

After autograft, 1-, 2- and 4-channel conduit repair, FB-, DY-, and FB-DY-labeled profiles in the anterior horn in the spinal cord were found intermingled. Images of the differently labeled profiles are provided in Figure 7. The total number of labeled profiles was not significantly different after 1-, 2- and 4-channel conduit repair, but was significantly higher after autograft repair $(p<0.01)$. The percentage of double projections to both the tibial and peroneal nerve branch was calculated by dividing the total number of double labeled neurons by the total number of neurons (single-labeled (DY and FB) and double-labeled neurons). Interestingly, the percentage of double-labeled neurons was significantly smaller after 2-channel $(2.7 \% \pm$ $2.9 \%)$ and 4-channel conduit $(2.4 \% \pm 1.5 \%)$ repair, compared with single channel conduit repair $(7.1 \% \pm$ 2.7\%) (both $p<0.05)$, indicating less axonal dispersion after multichannel nerve tube repair.

\subsection{Ankle motion analysis}

The ankle angle at terminal stance and midstance was significantly decreased one week after the surgery in all experimental groups (Fig. 8B and C), while slowly it recovered over time, but did not recover fully. The angle at midswing did not significantly change after surgery, but nevertheless significantly, increased over 
time. At 16 weeks no significant differences were found between any experimental groups for the different angles.

\section{Discussion}

In this study we showed that almost all channels contained fascicles with myelinated fibers. The amount of regeneration after repair with the different types of conduits was not significantly different despite the reduction in the total cross-sectional area for axons to grow into for multichannel nerve tubes. The ratios of total channel area for the 1-channel conduits versus 2-, 4- and 7-channel conduits are 4.1, 2.1 and 1.9, respectively. Similar findings were also observed in a previous study, though these results were limited by extensive swelling and collapse of the biomaterial poly(lactic co-glycolic acid) (PLGA) in the study. CMAP examinations offer an important index for the conduction function of peripheral nerve [2,28-31]. In this study, we observed the highest CMAP amplitude of autograft repair in both plantar foot muscles and dorsal muscles. This is consistent with its highest number of regenerated axons. One-channel and 4-channel conduit groups showed similar fiber diameter and myelination thickness to the autograft group. More immature fibers were seen in 2- and 7-channel and NeuraGen ${ }^{\circledR}$ conduit groups with smaller fiber diameter and myelination thickness which is related to the inferior amplitude values in the CMAP test.

Previous studies have reported on reinnervation after single-lumen nerve tube repair using various methods $[2,7,8,32-34]$. The main goal of this research was to investigate whether multichannel nerve conduits present a permissive microenvironment for axonal growth. Towards this goal, we developed an innovative moulding technique to fabricate 1-, 4-, and 7-channel conduits from a high concentration collagen solution. The conduits were crosslinked with 30mM EDC and 10m M NHS. A series of collagen-based nerve conduits with multiple dimensionally stable sub-millimetre diameter channels was fabricated in this study to facilitate nerve guidance and limit dispersion. The results of this study clearly demonstrate the potential influence that multichannel nerve tube structure have on limiting axonal dispersion across the conduit without decreasing the quantitative results of regeneration. After multichannel collagen conduit repair the percentage of motor neurons with double projections to both the tibial and peroneal nerve branch was three times smaller compared with single channel collagen conduit repair (2.4\% vs $7.1 \%)$, while the total number of regenerated axons and motor neurons was equal. However, the percentage may indicate only part of the axonal 
dispersion that occurs during regeneration across the conduit. In addition, there may be motor neurons with single projections that have dispersed and regenerated to the wrong target organ. The misdirection after autograft repair could be the result of most axons being misrouted at the coaptation sites [35]. The mechanism of pruning has been investigated in detail for motor versus sensory regeneration [36,37], and pruning may also affect the reinnervation of plantar and dorsiflexion muscles by tibial and peroneal motor neurons respectively. Pruning might thus be a mechanism to correct misdirection. An additional advantage of the multichannel conduit is that it provides more internal lining for cell attachment and/or the controlled release of growth factors compared with single lumen conduits. The introduction of supportive cells, growth factors in microspheres and/or viral vectors expressing growth factors in the multichannel conduits may not only help to overcome the dispersion at the nerve-channel and channel-nerve junctions, but it may also increase the number of regenerated axons.

Finally, it should be noted that the quantitative results of regeneration in our study were still best for autograft repair. Although this did not result in a better functional outcome, it is important to realize that the ideal alternative for the autograft should perform better than the autograft. Only in selective cases of nerve graft repair such as in the repair of small nerve defects $(<3 \mathrm{~cm})$ in small nerves (for example digital nerves) the advantages of a conduit that is right-off-the-shelf available can outweigh the advantages of an autograft that consists of longitudinally orientated collagen tubes that contain Schwann cells.

\section{Conclusions}

In this study, we investigated the influence of channel number on the axonal regeneration using collagen conduits with multiple sub-millimeter diameter channels. Nerve morphometry and compound muscle action potential studies showed that the fabricated 1-channel and 4-channel conduits are superior to other types of conduits in axonal regeneration. Simultaneous tracing showed a significantly lower percentage of motor neurons with double projections after 2- and 4-channel compared with 1-channel conduit repair. This study demonstrated the influence of multichannel guidance on limiting axonal dispersion without decreasing quantitative results of regeneration. The overall results suggested that 4-channel collagen conduit is a favorable structure for peripheral nerve regeneration. 


\section{Acknowledgement}

Enterprise Ireland - Proof of Concept Grant (PC/2007/027)

Science Foundation Ireland - Research Frontiers Program, under Grant Number (08/RFP/ENM1218)

Science Foundation Ireland - The Short Term Travel Fellowship (STTF) supplement

Leiden University Fund (LUF)/ Slingelands 


\section{Figure legends}

Fig. 1.

Fabrication of multichannel collagen nerve conduits. (A) Collagen conduit was fabricated on the molds with stainless steel wires insertion. (B) Dimension of the molds for conduit fabrication. (C) Diagrams show the suture of nerve stumps to the collagen conduits. (D) The transverse images of multichannel conduits. Scale bar, 1mm. (E) Images show the 1-cahnnel (1) and 4-channel (2) collagen nerve conduits. Arrows show the sleeves at the each end of nerve conduit for nerve stump insertion and suturing.

Fig. 2.

Microscopic images (5× magnification) of sections stained with toluidine blue taken through the middle of an (A) 1-, (B) 2-, (C) 4-, and (D) 7-channel collagen conduit, (E) an NeuraGen ${ }^{\circledR}$ single channel conduit and (F) autograft. Scale bar, 500 $\mu$ m.

Fig. 3.

Microscopic images (40x magnification) of sections stained with toluidine blue taken through the middle of an (A) autograft, (B) 1-, (C) 2-, (D) 4-, and (E) 7-channel collagen conduit and (F) an NeuraGen ${ }^{\circledR}$ single channel conduit. Clearly visible is the larger diameter of myelinated fibers in the autograft, and 1- and 4-channel conduits, compared with the 2and 7-channel conduits, and the small dispersed groups of fibers in the NeuraGen ${ }^{\circledR}$ conduit. Scale bar, $30 \mu \mathrm{m}$.

Fig. 4.

Microscopic images (40x magnification) of sections stained with 1\% phenylenediamine taken through the middle of an (A) autograft, (B) 1-, (C) 2-, (D) 4-, and (E) 7-channel collagen conduit and (F) an NeuraGen ${ }^{\circledR}$ single channel conduit. Scale bar, $30 \mu \mathrm{m}$.

Fig. 5.

Results of nerve morphometry after autograft, 1-, 2-, 4-, 7-channel collagen conduit and NeuraGen ${ }^{\circledR}$ conduit repair for (A) the mean number of myelinated fibers $(*, \mathrm{P}<0.01$, vs all the conduit groups), (B) the mean myelinated fiber density $(*, \mathrm{P}<$ 0.05 , vs the autograft, single channel and 4-channel tube graft groups; $\S, P<0.01$, vs all the other groups), (C) mean myelinated fiber size $\left(*, \mathrm{P}<0.01\right.$, vs 2 -channel, 7 -channel, NeuraGen ${ }^{\circledR}$ conduits; $\S, \mathrm{P}<0.05$, vs NeuraGen ${ }^{\circledR}$ conduit group), 
(D) mean myelin thickness $\left(*, P<0.05\right.$, vs 7-channel and NeuraGen ${ }^{\circledast}$ conduit groups; $\S, P<0.05$ vs NeuraGen ${ }^{\circledR}$ conduit group). Scale bar, $30 \mu \mathrm{m}$.

Fig. 6.

Results of the mean amplitude for compound muscle action potentials recorded in plantar and dorsal foot muscle respectively in experimental group 1 ( $A$ and $B$ ). In panels $C$ and $D$ results are also presented for CMAP amplitudes in the animals in experimental group 2 that were trained with a treadmill $(*, \mathrm{P}<0.05)$.

Fig. 7.

A-D: Fluorescent microscopic images (10× magnification, DAPi filter) of longitudinal section taken through anterior horn after (A) autograft repair, (B) 1-channel, (C) 2-channel, and (D) 4-channel conduit repair. E-H: Fluorescent microscopic images (20× magnification, DAPi filter) of (E) a single FB-labeled profile (with blue cytoplasm and dark nucleus, arrow a), (F) single DY-labeled profile (with yellow nucleus and dark cytoplasm, arrow b), and (G and H) FB-DY double-labeled profiles (with yellow nucleus and blue cytoplasm. G, arrow c; H, arrow d). I: Results of simultaneous tracing for the mean number of FB-labeled, DY-lableed, and FB-DY double-labeled profiles after autograft, 1-, 2-, and 4-channel conduit repair. $\mathrm{J}$ : Results of simultaneous tracing for the percentages of double projections after autograft, 1-, 2-, and 4-channel conduit repair $(*, \mathrm{P}<0.05$, vs 2 -channel and 4-channel conduit groups). Scale bar, $200 \mu \mathrm{m}$.

Fig. 8.

Recovery of ankle motion for the angles at (A) initial contact, (B) mid-stance, (C) terminal stance, and (D) mid-swing after autograft, 1-, 2-, 4-, and 7-channel and NeuraGen ${ }^{\circledR}$ conduit repair.

\section{Supplemental Fig. 1.}

Surgical images show repaired sciatic nerves with nerve conduit implantations. (A)-(C), Transected nerves were repaired with (A) 1-channel conduit, (B) 4-channel conduit and (C) NeuraGen ${ }^{\circledR}$ collagen conduit. (D)-(F), Images of sciatic nerves 16 weeks post repair. (D) 1-channel conduit repair, (E) 2-channel conduit repair, (F) 4-channel conduit repair.

\section{Supplemental Fig. 2.}

Surgical images for retrograde tracing study. (A) Sixteen weeks post sciatic nerve repair with 4-channel conduit. (B) Insertion of proximal end of transected tibial nerve in the cup with fast blue dye. (C) Insertion of proximal end of transected peroneal nerve in the cup with diamidino yellow. 


\section{References}

1. Jiao $\mathrm{H}$, Yao J, Yang $\mathrm{Y}$, Chen $\mathrm{X}$, Lin $\mathrm{W}$, Li Y, et al. Chitosan/polyglycolic acid nerve grafts for axon regeneration from prolonged axotomized neurons to chronically denervated segments. Biomaterials 2009;30:5004-18.

2. Yang Y, Ding F, Wu J, Hu W, Liu W, Liu J, et al. Development and evaluation of silk fibroin-based nerve grafts used for peripheral nerve regeneration. Biomaterials 2007;28:5526-35.

3. Matsumoto K, Ohnishi K, Kiyotani T, Sekine T, Ueda H, Nakamura T, et al. Peripheral nerve regeneration across an $80 \mathrm{~mm}$ defect bridged by a polyglycolic acid (PGA)-collagen tube filled with laminin-coated collagen fibers: a histological and electrophysiological evaluation of regenerated nerves. Brain Res 2000;868:315-28.

4. Evans GR, Brandt K, Katz S. Bioactive poly (L-lactic acid) conduits seeded with Schwann cells for peripheral nerve regeneration. Biomaterials 2002;23:841-8.

5. Toba T, Nakamura T, Lynn AK, Matsumoto K, Fukuda S, Yoshitani M, et al. Evaluation of peripheral nerve regeneration across an 80mm gap using a polyglycolic acid (PGA)-collagen nerve conduit filled with laminin-soaked collagen sponge in dogs. Int J Artif Organs 2002;25:230-7.

6. Freier T, Montenegro R, Shan Koh H, Shoichet MS. Chitin-based tubes for tissue engineering in the nervous system. Biomaterials 2005;26:4624-32.

7. Kim YT, Haftel VK, Kumar S, Bellamkonda RV. The role of aligned polymer fiber-based constructs in the bridging of long peripheral nerve gaps. Biomaterials 2008;29:3117-27.

8. Bellamkonda RV. Peripheral nerve regeneration: an opinion on channels, scaffolds and anisotropy. Biomaterials 2006;27:3515-8.

9. Jiang BG, Yin XF, Zhang DY, Fu ZG, Zhang HB. Maximum number of collaterals developed by one axon during peripheral nerve regeneration and the influence of that number on reinnervation effects. Eur Neurol 2007;58:12-20.

10. de Ruiter GC, Spinner RJ, Yaszemski MJ, Windebank AJ, Malessy MJ. Nerve tubes for peripheral nerve repair. Neurosurg Clin N Am 2009;20:91-105. 
11. Meek MF, Coert JH. US Food and Drug Administration/Conformit Europe-approved absorbable nerve conduits for clinical repair of peripheral and cranial nerves. Ann Plast Surg 2008;60:110-6.

12. Schlosshauer B, Dreesmann L, Schaller HE, Sinis N. Synthetic nerve guide implants in humans: a comprehensive survey. Neurosurgery 2006;59:740-7.

13. Brushart TM, Mathur V, Sood R, Koschorke GM. Joseph H. Boyes Award. Dispersion of regenerating axons across enclosed neural gaps. J Hand Surg Am 1995;20:557-64.

14. Hadlock T, Sundback C, Hunter D, Cheney M, Vacanti JP. A polymer foam conduit seeded with Schwann cells promotes guided peripheral nerve regeneration. Tissue Eng 2000;6:119-27.

15. de Ruiter GC, Onyeneho IA, Liang ET, Moore MJ, Knight AM, Malessy MJ, et al. Methods for in vitro characterization of multichannel nerve tubes. J Biomed Mater Res A 2008;84:643-51.

16. de Ruiter GC, Spinner RJ, Malessy MJ, Moore MJ, Sorenson EJ, Currier BL, et al. Accuracy of motor axon regeneration across autograft, single-lumen, and multichannel poly(lactic-co-glycolic acid) nerve tubes. Neurosurgery 2008;63:144-53.

17. Giannini C, Dyck PJ. The fate of Schwann cell basement membranes in permanently transected nerves. J Neuropathol Exp Neurol 1990;49:550-63.

18. Sorenson EJ, Windebank AJ. Relative importance of basement membrane and soluble growth factors in delayed and immediate regeneration of rat sciatic nerve J Neuropathol Exp Neurol 1993;52:216-22.

19. Colin W, Donoff RB. Nerve regeneration through collagen tubes. J Dent Res 1984;63:987-93.

20. Laquerriere A, Yun J, Tiollier J, Hemet J, Tadie M. Experimental evaluation of bilayered human collagen as a dural substitute. J Neurosurg 1993;78:487-91.

21. Wissink MJ, Beernink R, Pieper JS, Poot AA, Engbers GH, Beugeling T, et al. Immobilization of heparin to EDC/NHS-crosslinked collagen. Characterization and in vitro evaluation. Biomaterials 2001;22:151-63.

22. Sakakima H, Yoshida $\mathrm{Y}$, Sakae $\mathrm{K}$, Morimoto N. Different frequency treadmill running in immobilization-induced muscle atrophy.and ankle joint contracture of rats. Scand J Med Sci Sports 2004;14:186-92.

23. O'Callaghan RM, Griffin EW, Kelly AM. Long-term treadmill exposure protects against age-related neurodegenerative change in the rat hippocampus. Hippocampus 2009;19:1019-29. 
24. Cavalcanti RA, da Pureza DY, de Melo MP, de Souza RR, Bergamaschi CT, do Amaral SL, et al. Low-intensity treadmill exercise-related changes in the rat stellate ganglion neurons. J Neurosci Res 2009;87:1334-42.

25. Fields RD, Le Beau JM, Longo FM, Ellisman MH. Nerve regeneration through artificial tubular implants. Prog Neurobiol 1989;33:87-134.

26. Dyck PJ, Dyck PJB, Engelstad J. Pathologic alterations of nerves. In: Dyck PJ, Thomas PK, editors. Peripheral Neuropathy. Philadelphia: Elsevier Saunders, 2005. p. 733-829.

27. de Ruiter GC, Spinner RJ, Alaid AO, Koch AJ, Wang H, Malessy MJ, et al. Two-dimensional digital video ankle motion analysis for assessment of function in the rat sciatic nerve model. J Peripher Nerv Syst 2007;12:216-22.

28. Wang $\mathrm{H}$, Sorenson EJ, Spinner RJ, Windebank AJ. Electrophysiologic findings and grip strength after nerve injuries in the rat forelimb. Muscle Nerve 2008;38:1254-65.

29. lida H, Schmelzer JD, Schmeichel AM, Wang Y, Low Pa. Peripheral nerve ischemia: reperfusion injury and fiber regeneration. Exp Neurol 2003;184:997-1002.

30. Chen MH, Chen PR, Chen MH, Hsieh ST, Huang JS, Lin FH. An in vivo study of tricalcium phosphate and glutaraldehyde crosslinking gelatin conduits in peripheral nerve repair. J Biomed Mater Res B Appl Biomater 2006;77:89-97.

31. Ozay R, Bekar A, Kocaeli H, Karli N, Filiz G, Ulus IH. Citicoline improves functional recovery, promotes nerve regeneration, and reduces postoperative scarring after peripheral nerve surgery in rats. Surg Neurol 2007;68:615-22.

32. Chen CJ, Ou YC, Liao SL, Chen WY, Chen SY, Wu CW, et al. Transplantation of bone marrow stromal cells for peripheral nerve repair. Exp Neurol 2007;204:443-53.

33. Wang X, Hu W, Cao Y, Yao J, Wu J, Gu X. Dog sciatic nerve regeneration across a 30-mm defect bridged by a chitosan/PGA artificial nerve graft. Brain 2005;128:1897-910.

34. Bodine-Fowler SC, Meyer RS, Moskovitz A, Abrams R, Botte MJ. Inaccurate projection of rat soleus motoneurons: A comparison of nerve repair techniques. Muscle Nerve 1997;20:29-37.

35. Witzel C, Rohde C, Brushart TM. Pathway sampling by regenerating peripheral axons. J Comp Neurol 2005;485:183-90. 
PAGE 18

36. Brushart TM. Preferential reinnervation of motor nerves by regenerating motor axons. J Neurosci 1988;8:1026-31.

37. Brushart TM. Motor axons preferentially reinnervate motor pathways. J Neurosci 1993;13:2730-8. 
Figure 1.

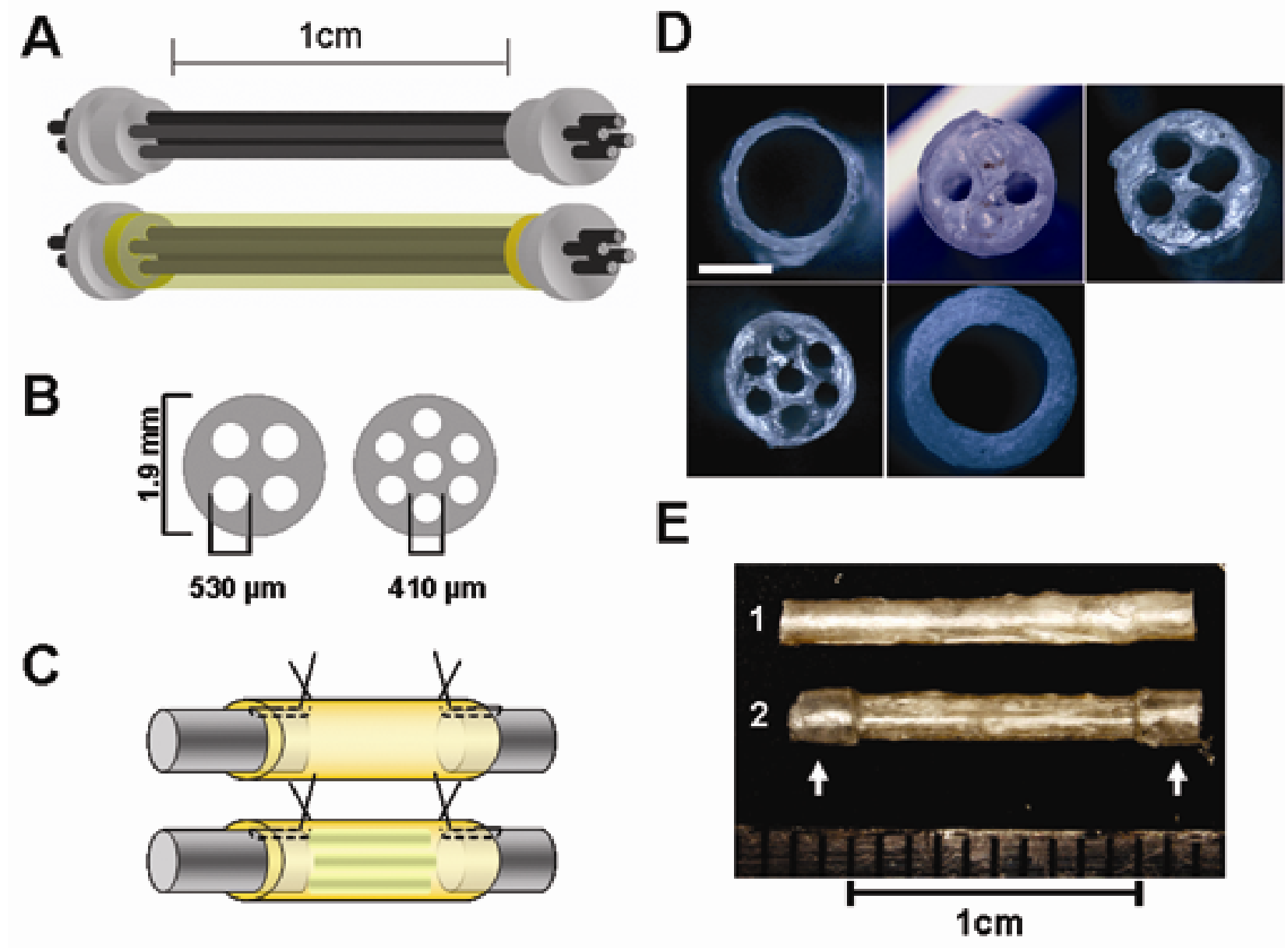


PAGE 20

Figure 2.

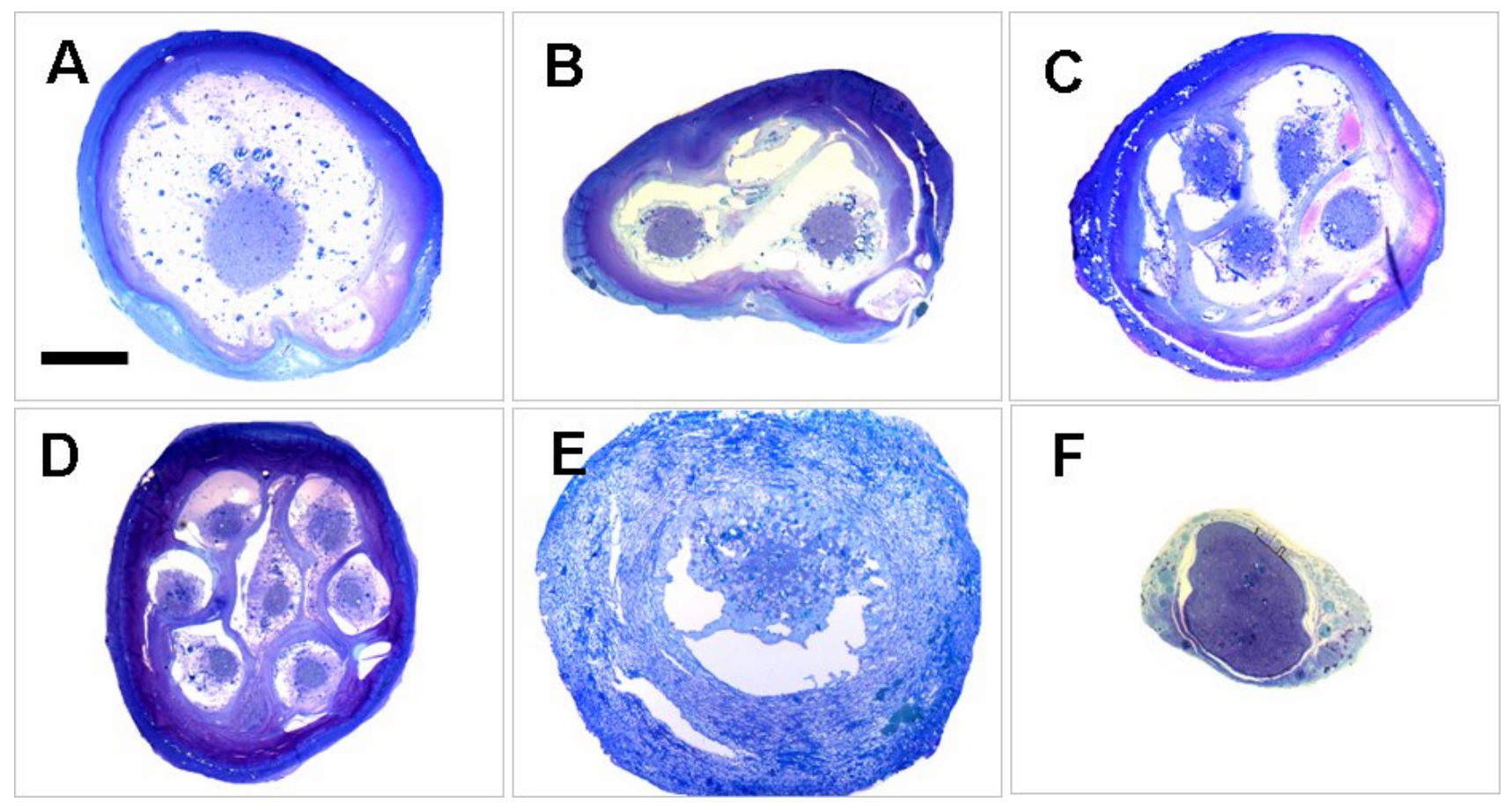


PAGE 21

Figure 3.
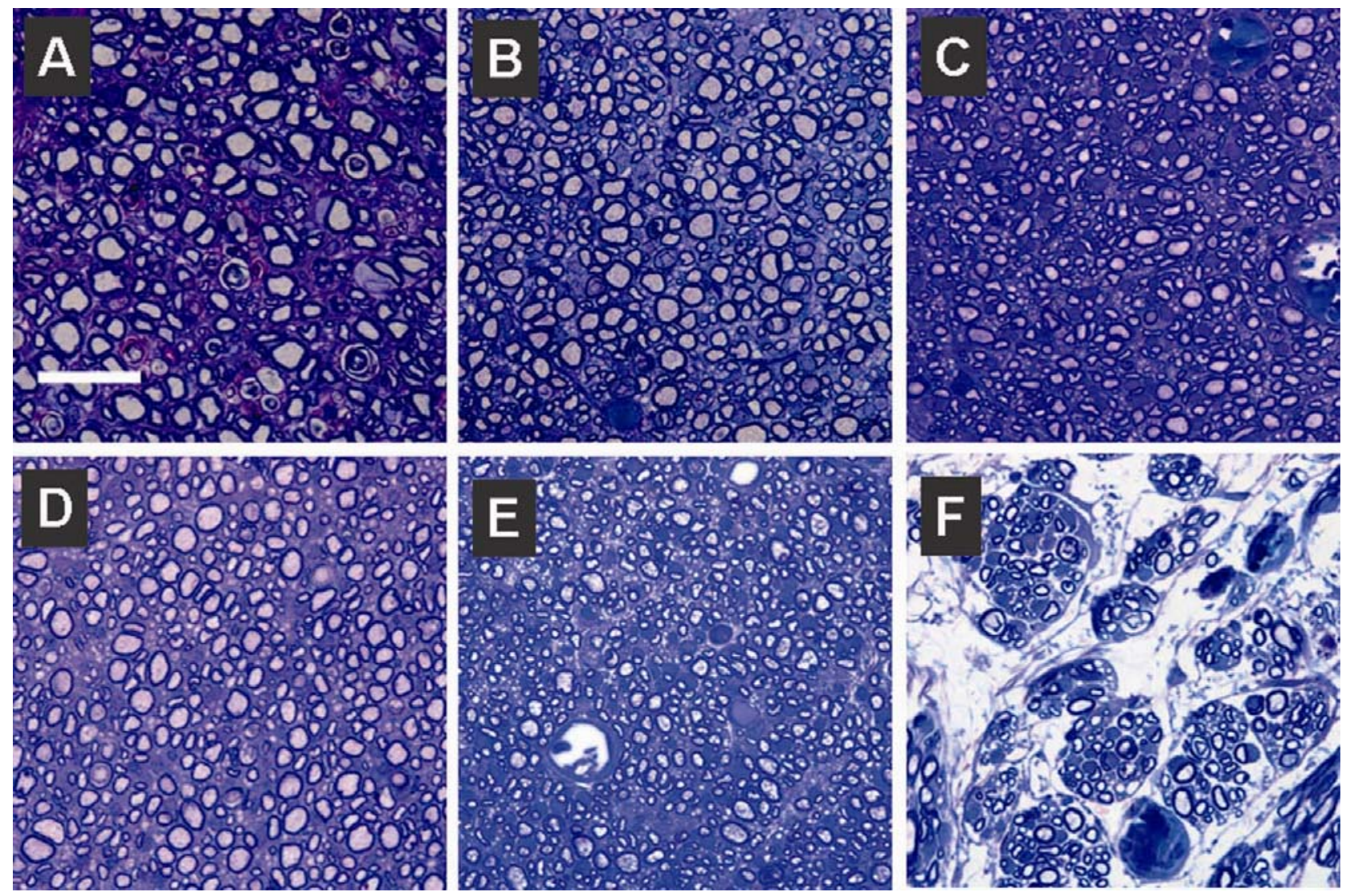
PAGE 22

Figure 4.
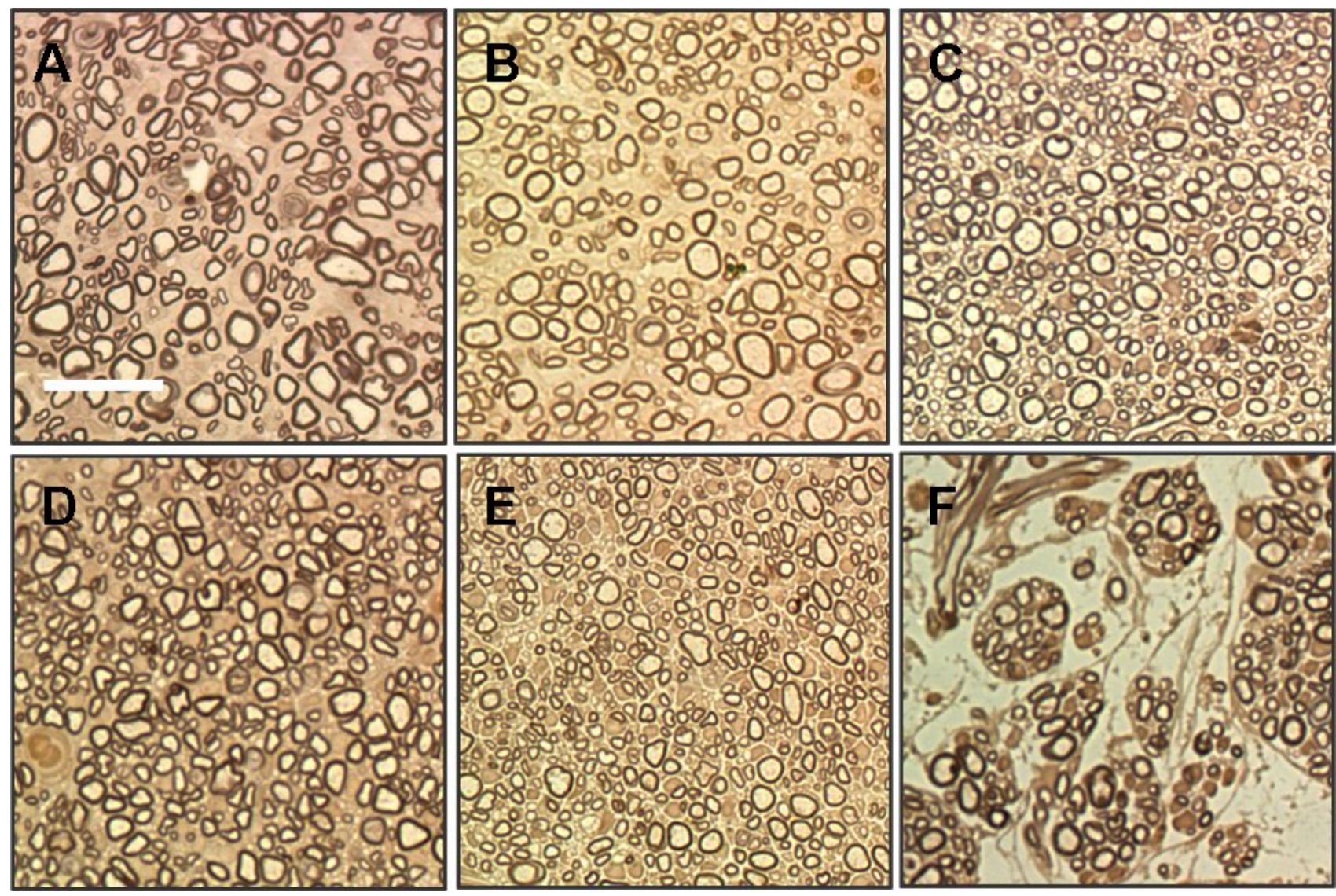
Figure 5.
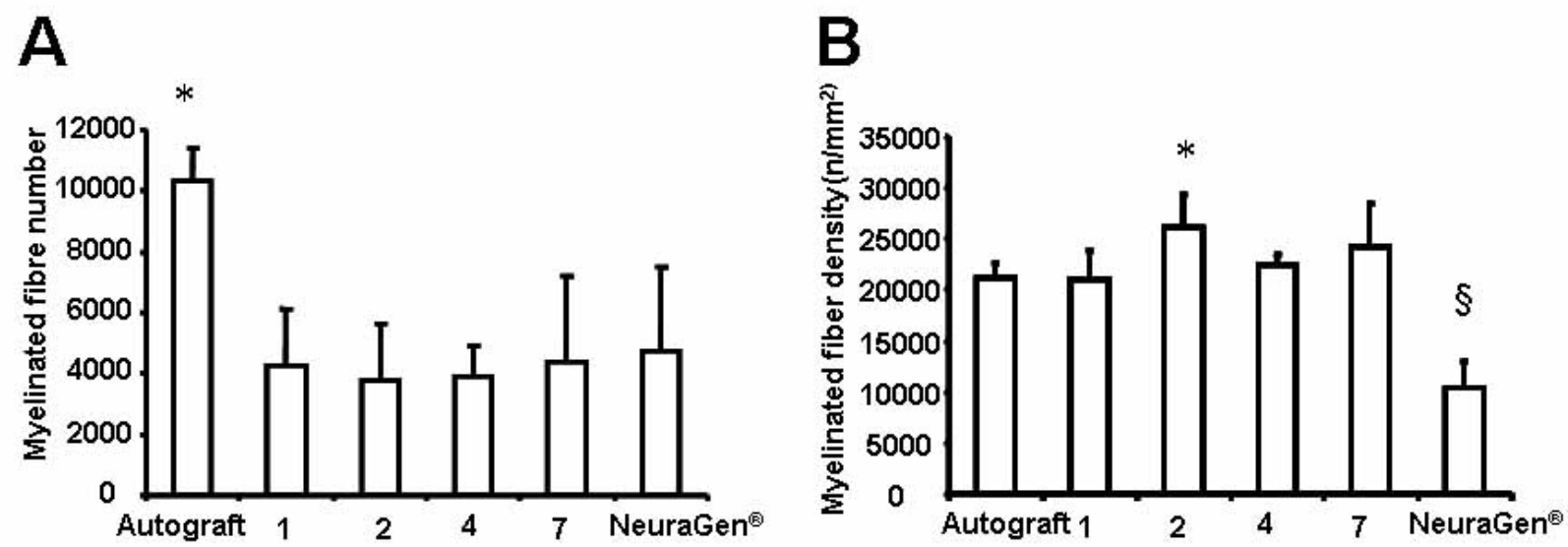

C

D
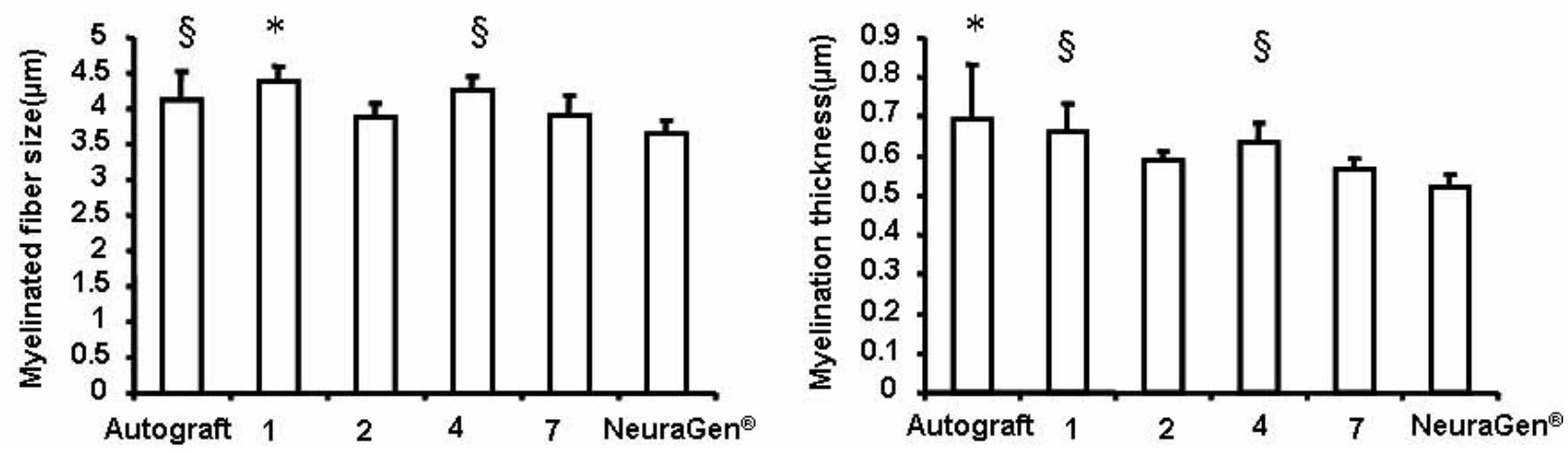
Figure 6.

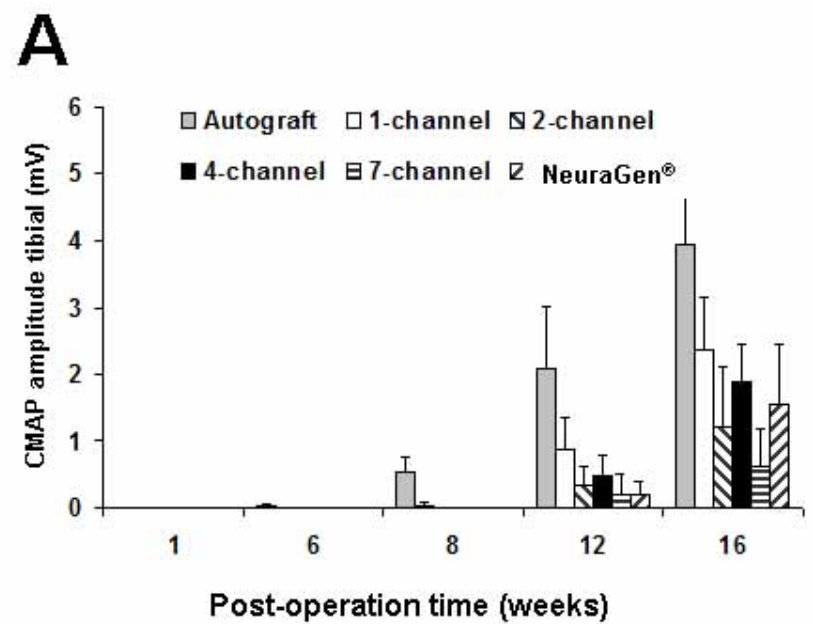

B

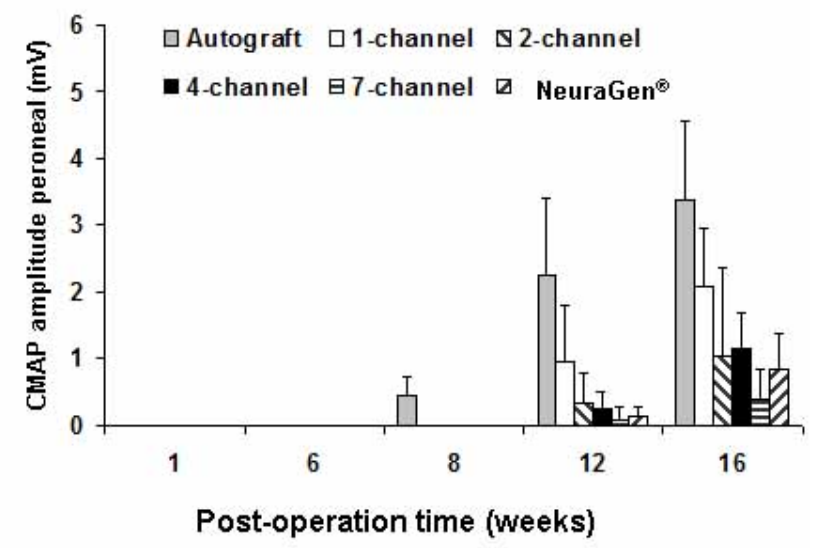

C

D
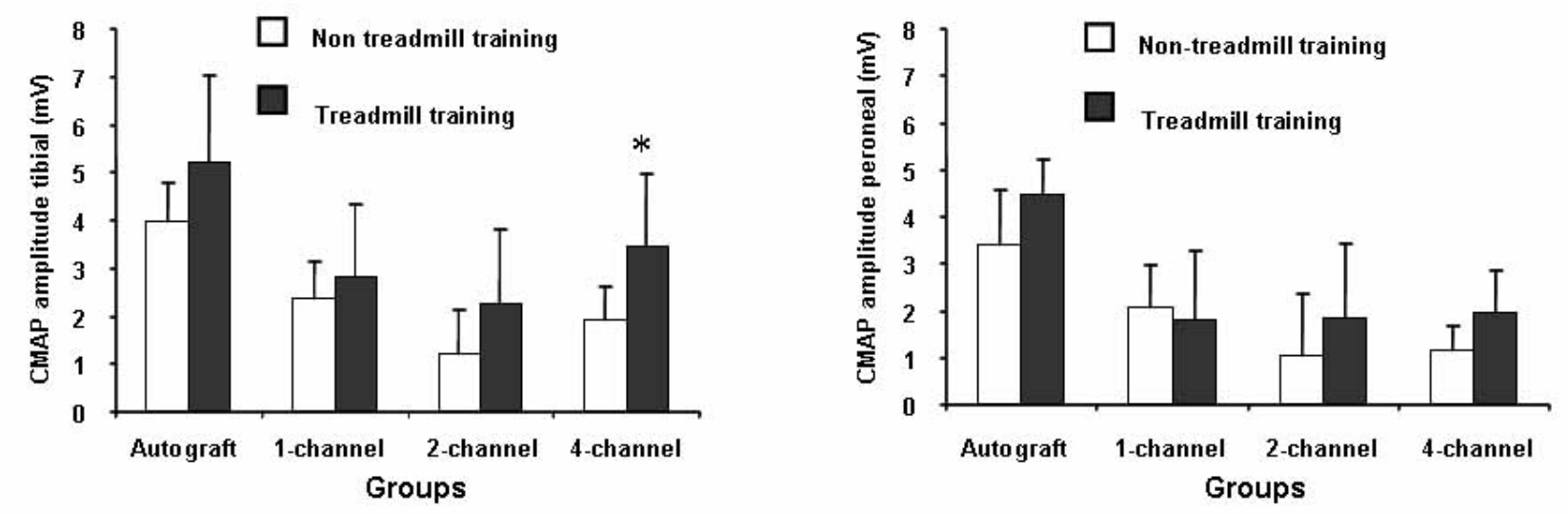
PAGE 25

Figure 7. 

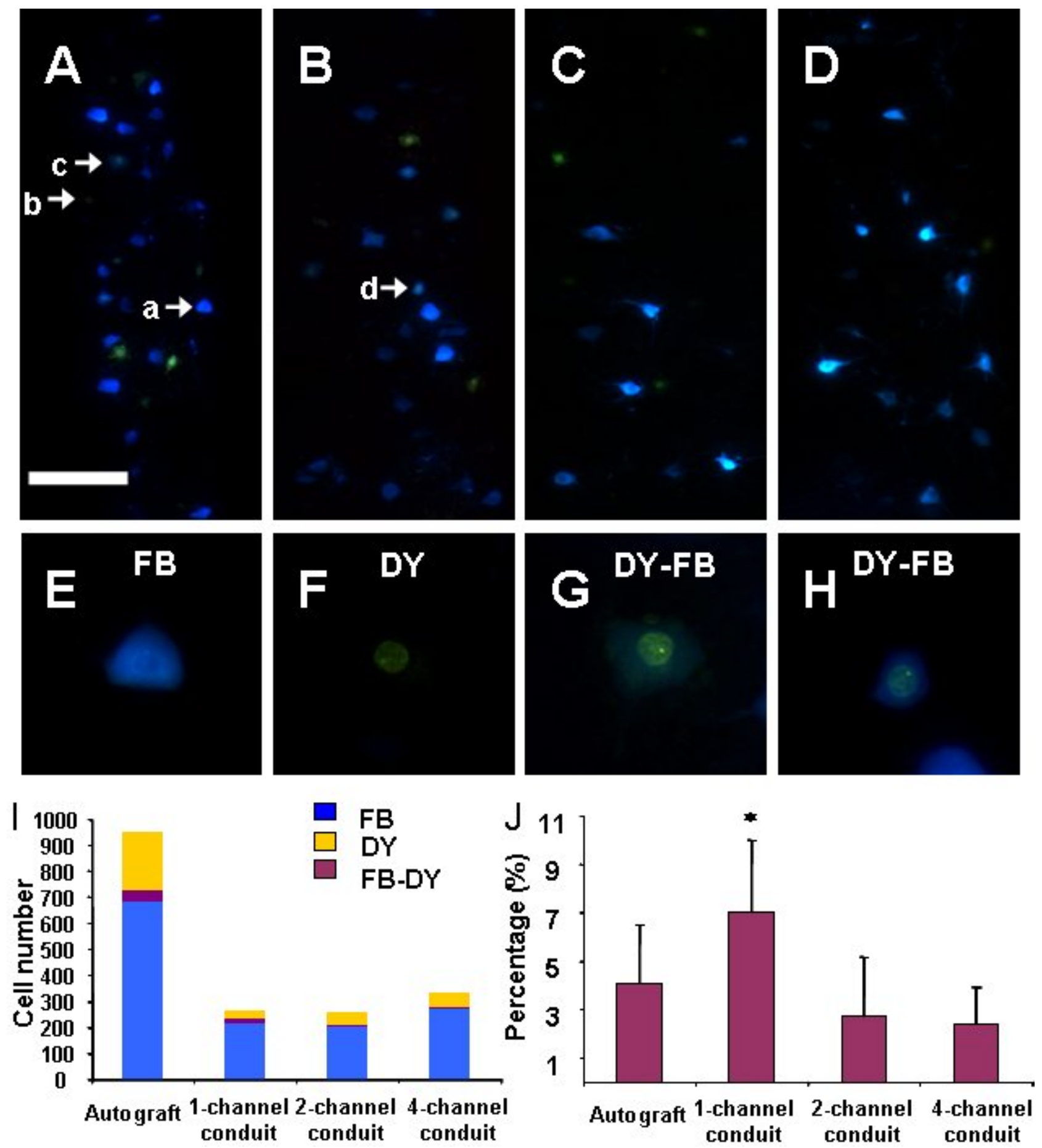
PAGE 27

Figure 8.

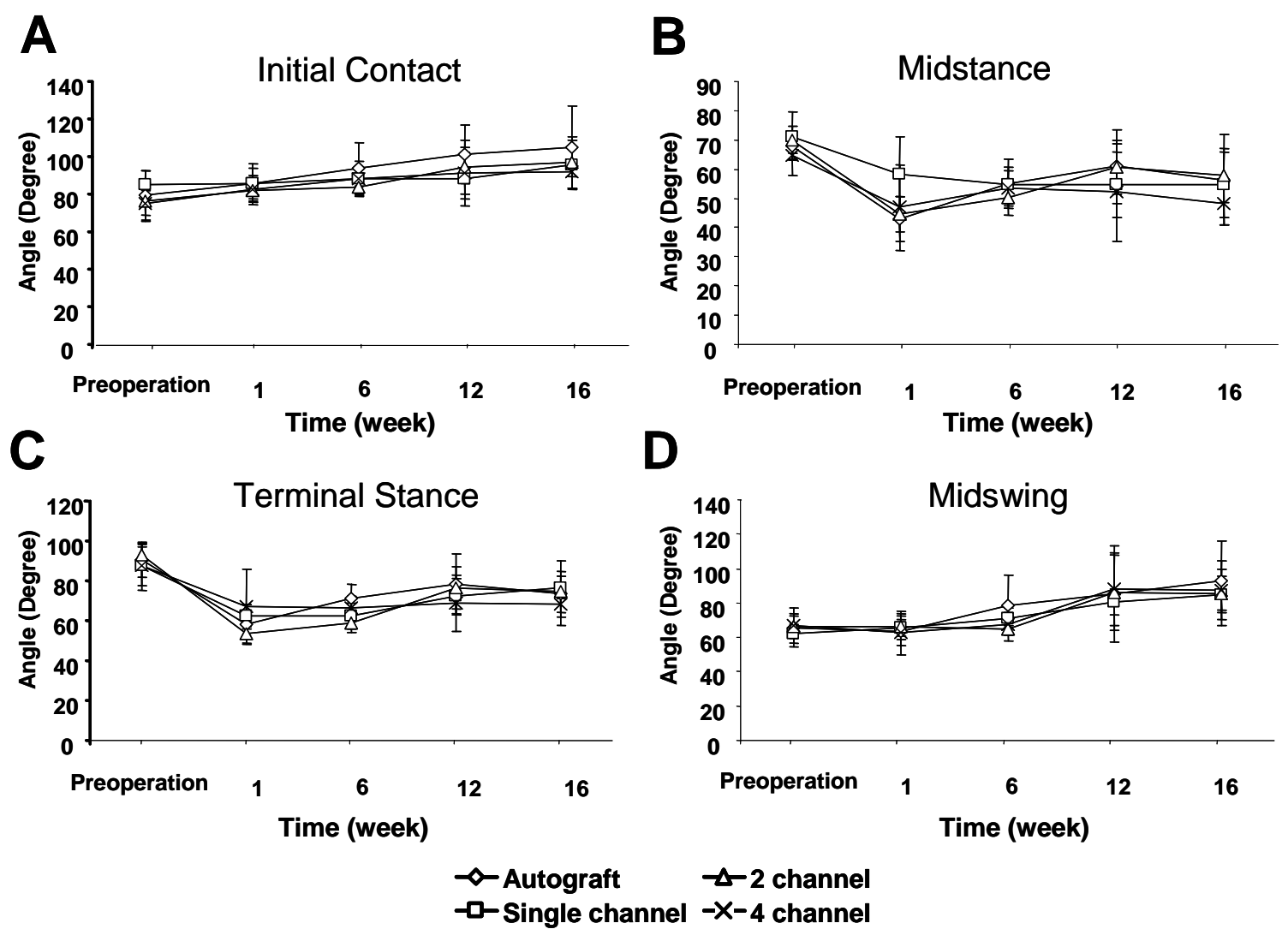


Supplemental figure 1
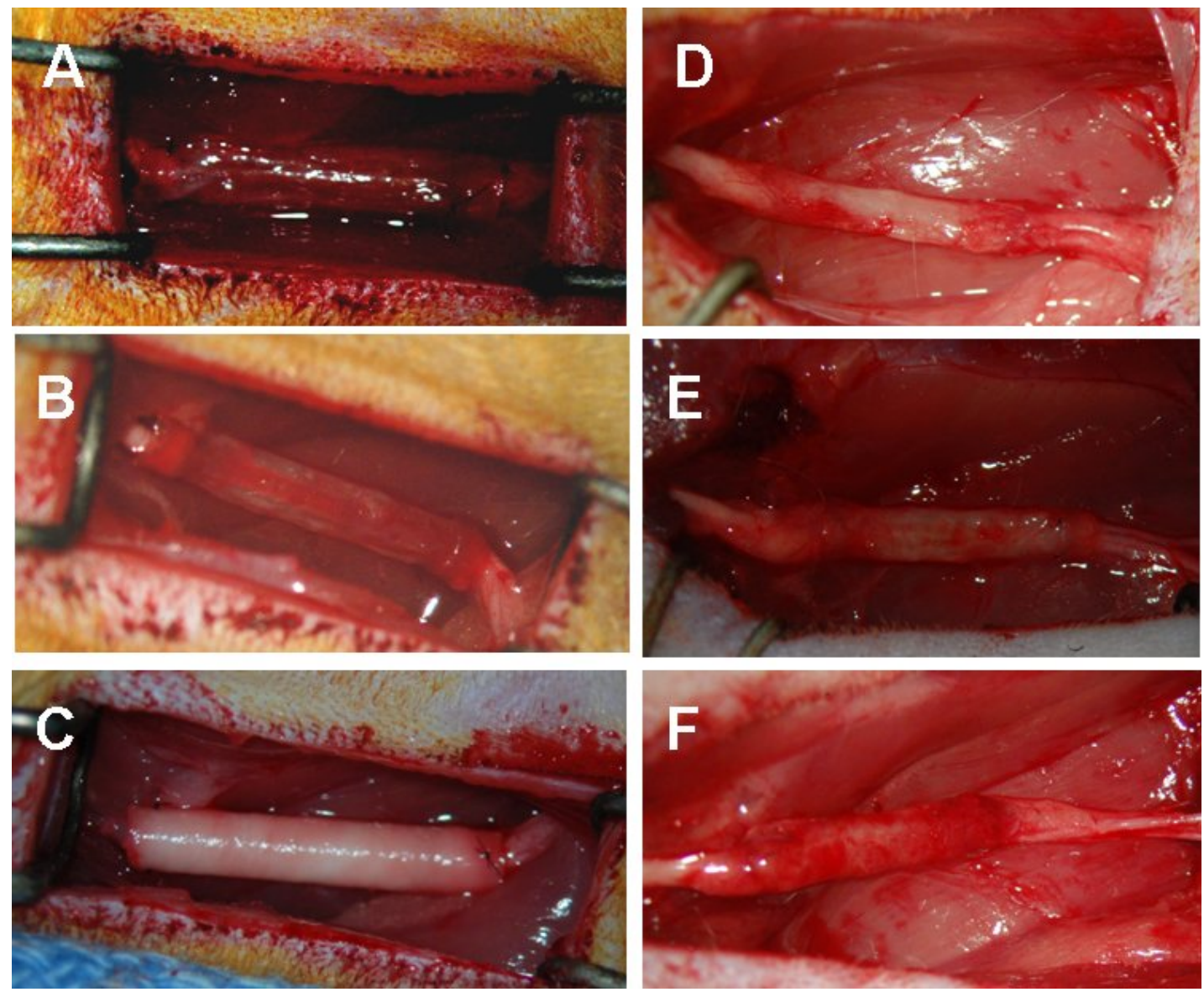
Supplemental figure 2
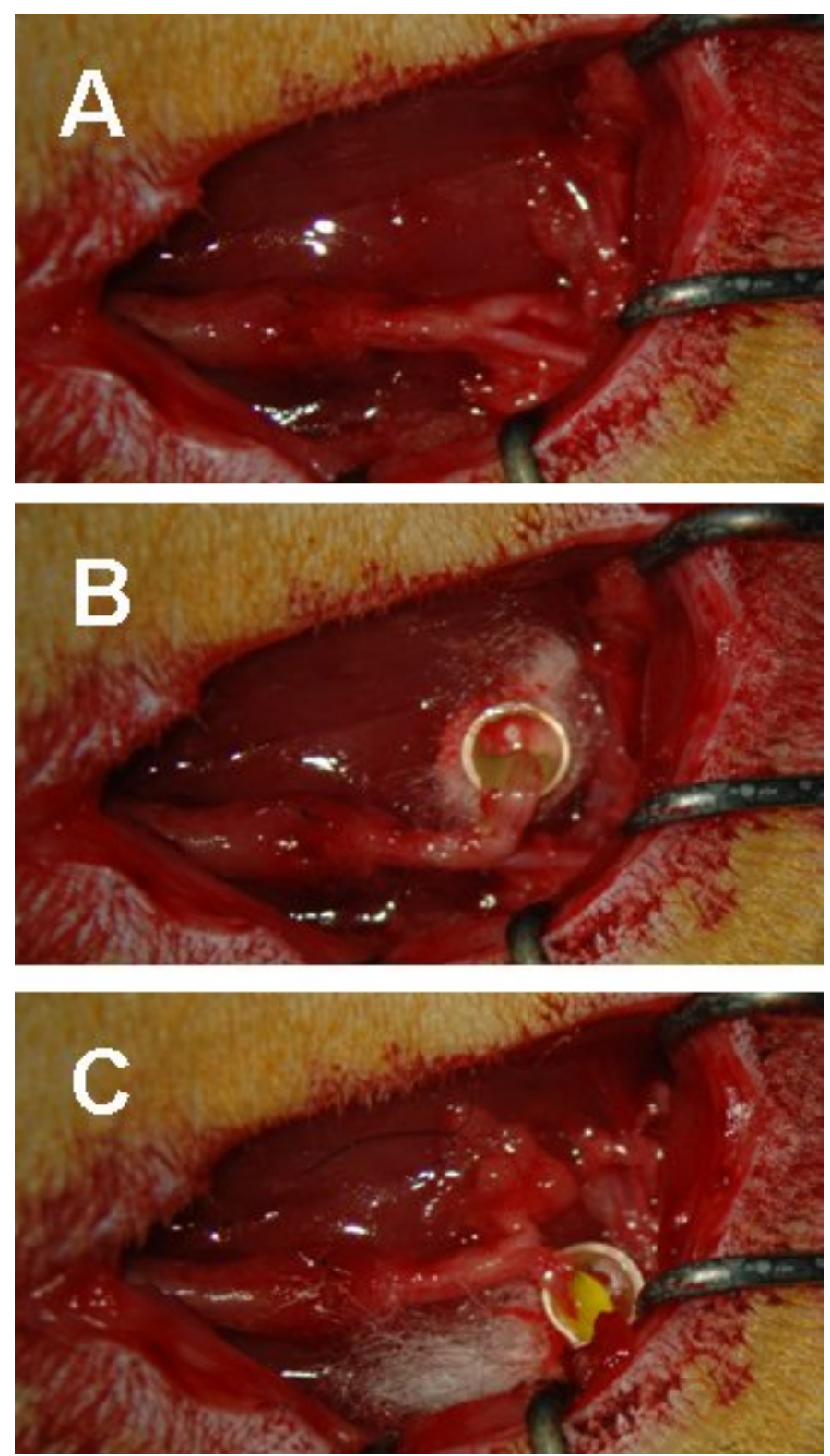